
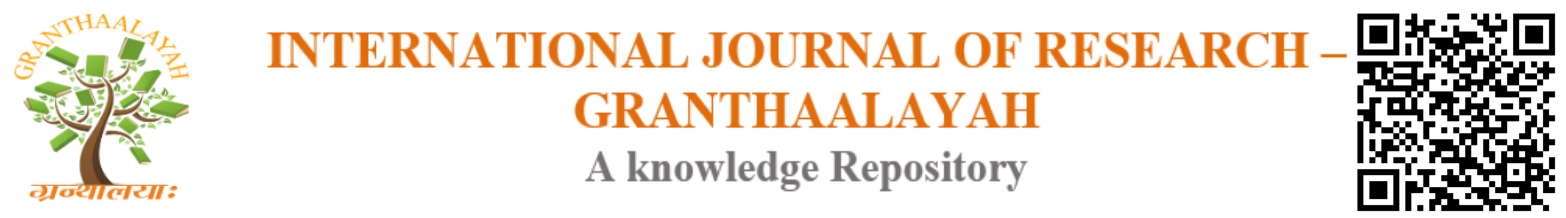

Social

\title{
ACCESSIBILITY ISSUES RELATING TO ELDERLY IN INDIA- A STUDY
}

\author{
V.R. Uma *1 \\ ${ }^{* 1}$ B.A.LL.M., UGC-NET, TS/APSET, Assistant Professor, Dr. Ambedkar Government Law \\ College, Puducherry, India
}

\begin{abstract}
Older people are the only growing segment of world's population. They are one of the important consumers and contributors to the economic and social lives of the member states of this world. As citizens, they should share the same rights as people of other ages to access to every part of our society. Yet, the reality of life is that older people face barriers in some of the most basic areas of life -areas which other members of our community can access at will - just because of their age. older people and indeed people from other age groups, face unnecessary discrimination in other parts of their lives and this is neither in the interests of individuals or in the interest of our economy and society. In an ageing society we need a cultural and policy framework which breaks down barriers to participation rather than erecting and permitting them, and maximises the ability of individuals to participate in economic and social activity, whatever their personal characteristics.
\end{abstract}

Keywords: Accessibility; Elderly; Issues.

Cite This Article: V.R. Uma. (2018). "ACCESSIBILITY ISSUES RELATING TO ELDERLY IN INDIA- A STUDY." International Journal of Research - Granthaalayah, 6(5), 255-262. https://doi.org/10.29121/granthaalayah.v6.i5.2018.1447.

\section{Introduction}

In a number of policy areas older people benefit from positive action, which seeks to address or compensate for the disadvantages that they face, particularly in the low levels of income they are expected to live on. Facilitating access and making better and more efficient use of services like health care, transportation, technology, housing etc may help older people to lead more independent lives, which in turn helps to maintain good health. It is important that services are accessible to all, and that older people (amongst others) are not excluded by new means of delivering services. Older people must be able to access fully the services they are entitled to, and it is important to ensure that everyone knows who to contact and what services are available to them. Accessibility issues should be a guideline for authorities when devising welfare programs for the elderly. ${ }^{1}$

\section{Access to Transportation}

\footnotetext{
${ }^{1}$ http://www.healthyageing.eu/steps/access-services.
} 
Access to public transport can help older people to avail themselves of goods, services, employment and other activities. With the current generation of older people being more active than previous generations of equivalent age, public transport will play a crucial role in maintaining their active life style even when they are unable to drive. They found that mobility is important in meeting essential utilitarian needs, but also enhancing social networks and social interaction, providing independence, denoting status, and exercising cognitive skills. It was found that the local transport system allowed the elderly group to visit family and friends, access appropriate services and to attend community activities, shopping and leisure. Access to healthcare, food shops, post offices and other cultural, social and leisure facilities (including libraries, leisure centres, non-food shops, town centres and places of worship) are other activities of travelling. For many of those no longer able to drive, public transport is an important alternative means of transport, taxis and lifts from family and friends. It is therefore vital that public transport facilities available are adequate to provide acceptable levels of mobility for the specific needs of older people. This is not only important for the individual well-being of older people; it also provides significant economic return due to improved quality of life especially by supporting social engagement and physical activity, hence improving mental and physical health. To make public transport an attractive alternative for older people, all the elements of the public transport chain need to be considered. These issues include: accessibility of bus, bus stop facilities, availability of information, ease of way finding, availability of toilets, etc. Old people are sensitive to service quality, including personal security, reliability, service frequency, continuity of the service, comfort, cleanliness, customer care, real time information and affordability of the fare.

Due to population growth, infrastructure in India has to keep up with the demographic change by providing accessible and affordable public transportation, which is vitally important. India boasts of a well-connected transportation system with trains, buses, metro systems, auto rickshaws and taxis in urban as well as, to a lesser extent, rural areas. Despite the plethora of transportation options, many of these services are beyond the reach of the elderly population. The large number of people utilizing public transportation is a major hindrance for the elderly. For example, in Chennai, the elderly complain of how government buses are always crowded. While there are seats reserved for the elderly in these buses, it is hard to avail of these services. In Mumbai, trains are the preferred means of transport because they are fast, cheap and reliable. However, they are extremely crowded which makes it really difficult for senior citizens to get in the train. Like the buses in Chennai, these trains too have reserved seating for the elderly. Another major issue is affordability. If elderly people cannot afford private transport, it is very difficult for them to commute or attend social, religious and family functions. Those who can afford it use the relatively expensive modes of transportation which include rickshaws and taxis. There are some of national guidelines for age-friendly transportation in place. These include two reserved seats for the elderly in the front of the bus, fare concessions and subsidized bus passes, $30 \%$ concessions on trains, separate counters for senior citizens, ramps at stations for greater accessibility, disability-friendly train coaches and fare concessions by several major public and private airlines. It is heartening to see that many cities and/or states go above and beyond these guidelines. For instance, Mumbai is currently petitioning for elderly-only compartments in all trains at the Bombay High Court. New Delhi, the country's capital, has introduced low-floor buses. ${ }^{2}$ Initiatives like these are great first steps towards accommodating the elderly population. Yet, it is important to remember that

\footnotetext{
${ }^{2}$ Namratha Rao, https://globalhealthaging.org ,30.12.2014.
} 
transportation is but one aspect of infrastructure that needs to be worked on. A cross-sectional approach, incorporating sectors such as housing, education, roads, law-enforcement and town planning, is necessary to provide an easier and holistic lifestyle for the elderly population in India.

\section{Accessibility to Good Environment}

The quality and accessibility of the environment in which an older person lives can have a significant bearing on how active they are in society. Generally, the more accessible and agefriendly an environment is, the more active older people may be. Good health is associated with access to green areas and the time spent outdoors. Although older people may have physical difficulties, they often wish to be more active and mobile. Environmental threats such as pollution, as in Delhi, may also affect older people disproportionately. Airborne pollution is responsible for one of the heaviest burdens on public health systems, with a major portion of elderly people suffering from respiratory problems, many of whom are socio-economically deprived. For this reason it's important to promote safe, comfortable and accessible areas for older people, which requires policy makers to take transport, housing, social participation, community services, outdoor spaces and public buildings into consideration in their decision making. Relatively minor changes to the outdoor environment and public spaces can enable older people to be more active. ${ }^{3}$

\section{Access to Nutrient Food}

Good nutrition plays a significant role in determining the well-being of older people, and in delaying and reducing the risk of contracting disease. Eating too few fruits and vegetables is responsible for close to three million deaths worldwide every year. In addition, dietary fat seems to be associated with various cancers, and nutritionally unbalanced diets, which are often associated with diabetes, can play a significant role in increasing the risks of developing coronary heart disease. Many of the diseases suffered by older persons are a result of dietary factors, some of which have been in operation since infancy. Food preferences tend to be formed in childhood, and children who eat a balanced diet with lots of fruits and vegetables are likely to continue eating such a diet into adulthood. It is never too late to change dietary habits, though it is better to start eating a balanced diet early on in the life-course, though it should be noted that nutritional requirements change as a body ages, with calorific needs decreasing and nutritional needs increasing. One issue that needs to be tackled is the high price of foods rich in micronutrients, which discourages their consumption. ${ }^{4}$ In India, both state and central governments are making sure that the older and destitute do not suffer from the lack of basic food. Under the Antyodaya Scheme, the Below Poverty Line (BPL) families which also include older persons are provided food grains at the rate of $35 \mathrm{kgs}$. per family per month. The food grains are issued @ Rs.3/- per $\mathrm{kg}$. for rice and Rs.2/- per kg.for wheat. The persons aged 60 years above from the BPL category were given priority for identification. Under the Annapoorna Scheme being implemented by the States/UT Administration, $10 \mathrm{kgs}$. of food grains per beneficiary per month are provided free of cost to those senior citizens who remain uncovered under the old age pension scheme. Instructions have been issued for giving priority to the Ration Card holders who are over 60 years of age in Fair Price Shops for issue of rations. Also old people get monthly pensions to the tune of Rs.200.

\footnotetext{
${ }^{3}$ www. healthyageing. eu/steps/environment-and-accessibility.

${ }^{4}$ http://www. healthyageing.eu/steps/diet-and-nutrition.
} 
There is a demand to increase this to Rs.2000 keeping in mind of the inflation. Some state governments are already providing pension of Rs. 1000 per month.

\section{Access to learning}

There is a strong link between learning and better health, particularly in older people. The concept of life-long learning doesn't just mean obtaining employment-related qualifications; it also means promoting learning throughout the life course, for the well-being and enjoyment of all. Participating in adult learning courses is a form of civic participation, and can lead on in turn to involvement in voluntary activities and larger social networks - all of which are associated with improved health. And the benefits are not limited to individuals: better health and increased participation in society means reduced healthcare costs and a greater contribution to society as a whole. Levels of participation in education tend to decrease with age, though it is never too late to learn new skills and knowledge. This poses a challenge to policy makers, who need to ensure that opportunities to access, retrain and learn new skills are available to all throughout the life. The governments have realised the importance re-qualifying elder or retired people have taken steps in this regard by re-educating them. However, it is limited to western countries and urban areas of developing countries. ${ }^{5}$

\section{Access to Re-Employment}

Employment and other activities such as volunteering are associated with the maintenance of good health of older people. They help avoid alienation and social exclusion and increase levels of exercise, social interaction and connections with the community. Voluntary work needs to be promoted on its own merits, and not treated as a form of unpaid work. One notable barrier that older people face is age discrimination. Older people may need part-time work arrangements, and should be encouraged to take on new roles and learn new skills. Successfully increasing the olderworker employment rate may include incentives for employers to hire and retain older workers, with the understanding that labour-market shortages are foreseen across Europe, and there are many jobs that only older people can fill without significant investments in retraining. Retaining older workers should seen as an opportunity for employers to transfer knowledge and experience from older to younger workers, and mentoring schemes could play a key role in bridging the intergenerational divide and share skills and knowledge. Governments have been suggesting private sector in this regard to re-employ old workers on part time basis. ${ }^{6}$

\section{Access to Web \& Mobile Interface}

It is estimated that by 2050 one out of every five people will be over 60 years. ${ }^{7}$ This demographic shift is also impacting the workforce and the EC expects employment rates for older workers to "increase massively from $40 \%$ in 2004 to $59 \%$ in $2025^{8}$, that will need to be supported by ensuring lifelong access to suitable training. Also it makes obligatory on the part of elderly people to update their knowledge to keep themselves meaningfully employed. One key area in which they lag

\footnotetext{
${ }^{5}$ http://www.healthyageing.eu/steps/education-and-life-long-learning.

${ }^{6} \mathrm{http}$ ://www.healthyageing.eu /steps/employment-and-volunteering.

${ }^{7}$ https://www.w3.org, Web accessibility for older users.

${ }^{8} \mathrm{http}$ ://www.insightsonindia.com/2014/01/29/elderly-in-india-issues.
} 
behind is technology. Technologies are developing at a rapid pace, and affect every sphere of life. The ageing process can often result in elderly people experiencing multiple functional limitations. The commonly accepted limitations that often arise during the normal ageing process are: Vision decline, Hearing loss, Motor skill diminishment and Cognition effects. ${ }^{9}$ Although often considered a barrier to participation by older people, Information and Communication Technologies (ICTs) can play a key part in helping them to lead more independent and healthy lives in addition to keep them employed even after retirement. As we can see, by addressing accessibility, we could improve the quality of life of our elders in many ways. All Apps should be accessible in order to prevent social exclusion and to encourage the access of elderly people to the technologies. But, there are not many accessible applications on the market. Today, accessibility issues are a warning, but tomorrow they could be more alarming as long as society is getting older continues to increase with age.

Older people may benefit from age-friendly technologies, allowing them to live independently, monitor their health, create and maintain social networks, stay in contact with friends and family, access goods and services, and engage in work or voluntary activities. However, it is important to give older people adequate time to become accustomed to new technologies. E-inclusion in this respect is important, as it aims to prevent people from being 'left behind' in enjoying the benefits of ICT. All the evidence from the studies that report about the online activities of the elderly suggest that they do much the same online as most other age groups - that is, communication and information searches as well as using online services. Older web users do product research, purchase goods, make travel reservations, visit government Web sites, look up religious and spiritual information, online banking and searches are also related to hobbies and interests and health. It has been suggested that the provision of training courses to overcome the lack of experience with computers and the Web of many elderly people is a necessary short-term approach to encourage participation in the digital world. Computer and Web training can take the form of formal class-based training, but also informal training by friends and family who act as coaches. ${ }^{10}$ The Indian government has taken steps which enables the old people to communicate with others at a cheaper cost. Faults/complaints of senior citizens are given priority by registering them under senior citizens category with VIP flag, which is a priority category. Senior citizens are allowed to register telephone connection under N-OYT Special Category, which is a priority category.

\section{Access to Health Care}

Access to comprehensive, quality health care services is important for promoting and maintaining health, preventing and managing disease, reducing unnecessary disability and premature death, and achieving health equity for all old people. Access to health care impacts one's overall physical, social, and mental health status and quality of life. Access to health services means the timely use of personal health services to achieve the best health outcomes. It requires three distinct steps; gaining entry into the health care system usually through insurance coverage, accessing a location where needed health care services are provided (geographic availability) and finding a health care provider whom the patient trusts and can communicate with. Barriers to health services include high cost of care, inadequate or no insurance coverage, lack of availability of services and lack of culturally competent care. The other barriers are the doctors' lack of responsiveness to concerns(as

\footnotetext{
${ }^{9} \mathrm{http}: / / \mathrm{www} \cdot$ healthyageing .eu/steps /new-technologies.

${ }^{10}$ Web accessibility for older users, www.w3.org/TR/wai-age-literature.
} 
the per the perception of the patient), transportation problems , cost of transportation, income, street safety, fear of discovering a serious illness, not having time due to work responsibilities etc. ${ }^{11}$ Lack of sufficient government support, in third world countries, in the form of subsidising medical bills will surely decrease an older person's ability to be treated by a physician. It follows that rather than saving money, such a system would incur far greater expenses, as untreated conditions and lack of prevention would lead to greater severity of disease, which would promote more emergency visits and longer hospital stays. Due to financial constraints and insufficient medical insurance, sizeable percentage of adults over age 65 report that they have taken less medication than prescribed. Others have reported that they sometimes do not complete prescriptions, skip doses to make medication last longer, or spend less on food and heat so they can afford medicine. ${ }^{12}$ In addition to primary care and preventive services, emergency medical services are a crucial link in the chain of health care. Timeliness is the health care system's ability to provide health care quickly after a need is recognized. The delay in time between identifying a need for a specific test or treatment and actually receiving those services can negatively impact health and costs of care. ${ }^{13}$

\section{Access to Housing}

Everybody needs a decent, secure and affordable home - but at different points in our lives, we may require different things from our housing. Older people want comfortable and attractive housing alternatives that promote healthy and active lifestyles - but too often they find themselves in poor or inaccessible housing, in the wrong places. For many older people, it is too difficult to get simple home adaptations or repairs carried out quickly and affordably. Getting right housing for older people could have immense benefits for society and the economy. Many of the options that do exist are only available to a relatively small section of the older population. ${ }^{14}$ Better design and the deployment of new technology could help many older people achieve a high level of independence. Measures may include: the use of familiar objects and contrasting colours to make things easier to find and use; avoiding dazzling lights, having taps that automatically switch off, and using telecare to identify and respond to problems quickly. Some schemes have looked at fitting out flats with retro furniture that older people with dementia can find familiar and reassuring. Although older people generally require less space, they still want sufficient space to hold on to the things they value. They may also need storage space for a wheelchair or mobility vehicle. Damp, unfit and cold housing causes a range of health problems including respiratory conditions, arthritis, heart disease and stroke - as well as mental health problems, often caused by stress and anxiety. Hazards in the home and poor accessibility contribute to falls and accidents. Finding suitable housing or adapting current home, can make a huge difference to the quality of life of older people. In developed countries like UK, Local authorities are obliged to provide housing for older people. The local authority should assess the needs and give advice, provide information about services and support options available in the area of residence. In general, they take age into account when prioritising applications for housing. Some local authorities and

\footnotetext{
${ }^{11}$ Annette L. Fitzpatrick, Neil R. Powe, Lawton S. Cooper, Diane G. Ives, and John A. Robbin, Barriers to Health Care Access Among the Elderly and Who Perceives Them, American journal of public health 2004 October; 94.

12 Jill A. Bennett, Marna K. Flaherty-Robb, Issues Affecting the Health of Older Citizens: Meeting the Challenge, The online journal of issues in nursing; volume8-2003, No.2,May.

${ }_{13}$ Access to Health Services, www. healthypeople.gov.

${ }^{14}$ Joe Oldman, Housing in later life - Age UK, www.ageuk.org.uk.
} 
voluntary organisations provide specific housing for older people - usually community accommodation with special security features, such as wardens and security cameras. Each local authority allocates housing in accordance with its own housing allocation scheme. ${ }^{15}$

States in India such as Delhi, Kerala, Maharashtra and West Bengal have developed good quality old age homes. These old age homes have special medical facilities for senior citizens such as mobile health care systems, ambulances, nurses and provision of well-balanced meals. There are more than a thousand old age homes in India. Most of them offer free accommodation. Some homes work on a payment basis depending on the type and quality of services offered. Apart from food, shelter and medical amenities, old age homes also provide yoga classes to senior citizens. Old age homes also provide access to telephones and other forms of communication so that residents may keep in touch with their loved ones. Some old age homes have day care centres. These centres only take care of senior citizens during the day. For older people who have nowhere to go and no one to support them, old age homes provide a safe haven. These homes also create a family like atmosphere among the residents. They experience a sense of security and friendship when they share their joys and sorrows with each other.

Ministry of Social welfare and Employment has formulated two programs for the construction of old age homes. An Integrated Programme for Older: Under this Scheme, financial assistance up to 90\% of the project cost is provided to NGOs for establishing and maintaining Old Age Homes, Day Care Centres, Mobile Medicare Units and to provide non-institutional services to older persons. Another Scheme of Assistance to Panchayati Raj Institutions/ Voluntary Organizations/Self Help Groups for Construction of Old Age Homes/Multi-Service Centres for older persons - Under this Scheme, one time construction grant for Old Age Homes / Multi Service Centre is provided to non-governmental organizations on the recommendation of the State. The central government has also drawn up for the registration of all old-age homes, as the Centre at present only knows about those under it but not those under the states and private sector. The Centre would soon launch ratings for all home-care services which cater to the elderly and the sick to ensure proper service delivery. The other option of Senior Housing is for those who can afford to pay and enjoy a quality life. Senior housing, still in its nascent stages, is slowly and gradually gaining ground in India and is aimed at providing them a comfortable lifestyle. Developers operating in this segment are building projects that provide complete assisted living catering to their medical needs and providing them with services for all their day-to-day needs. There is a demand for such housing where retired people want to live in a community of like-minded people, with dignity in a home of their own and be provided for facilities. In the metros, elders are increasingly feeling the need for homes that provide care and an honourable lifestyle. For most elders, this has meant a reprieve from cumbersome housekeeping and intimidating domestic help. With rising crime rates, these homes offer security over everything else. Land acquisition, developers and industry bodies unanimously say, is the biggest hurdle in the growth of this segment. Projects meant for senior citizens are developed at a cost higher than the other projects, as additional facilities have to be provided. The maintenance of such projects is costlier, too. There is a lack of human resource that can be deployed in senior housing projects. For services, including medical, transportation, and security, there are no trained professionals to cater specifically to the seniors. The need of the hour is to create a workforce that is specially trained for such projects. This need can only be fulfilled by setting up training centres that cater specifically to this segment.

${ }^{15}$ http://www.citizensinformation.ie /en/housing /housing_grants_and_schemes/older_people. 
Industry experts are of the view that there is a lack of other facilities around the areas where these projects are coming up. There is a need to introduce a single-window mechanism for the elderly, to enable them to obtain all facilities, including life insurance, health insurance and information about senior living apartments under one roof. The government can also facilitate developers, by setting up hospitals, police stations, health camps, etc., near senior housing projects to boost its acceptability

\section{Conclusion}

In the context of a rapidly ageing population across the world, an increasing number of older people are confronted with age discrimination either directly like in health care, transportation or indirectly like in technology that they can't make use of. This ageing population will also be increasingly diverse as the life-course becomes increasingly varied, with different health status, different experiences, needs and expectations and different levels of resources being increasingly exhibited within the older age groups. Some older people will remain healthy and active for longer whilst others will experience health problems and require a range of services and support. Age is a characteristic that cannot be changed by the individual. The use of age as a limiting factor for access to goods, facilities and services will become increasingly difficult to justify. ${ }^{16}$ There is an urgent need for a shift in the understanding the needs of elderly people. Every effort should be made to keep them healthy and active. There are reports showing how age discrimination blights the lives of older people. Inaccessibility to some service may be just inconveniences to them, but some others are serious and can jeopardise health, income and living standards. Unless the world recognises and considers this issue seriously it cannot say that it fully recognises the human and political rights of older people or that it has made comprehensive efforts to include older people in society, despite the aspirations expressed in the Universal Declaration of Human Rights. It demonstrate $s$ that world has yet to come to terms with its changing demography and recognised that in an ageing society older people will be crucial to the economic and social development - as consumers, contributors and citizens.

*Corresponding author.

E-mail address: arunfamily1982@ gmail.com

${ }^{16}$ Age Barriers: Older people's experience of discrimination in access to goods, facilities and services, AGE - The European Older People's Platform December 2004, http://www.age-platform.eu. 